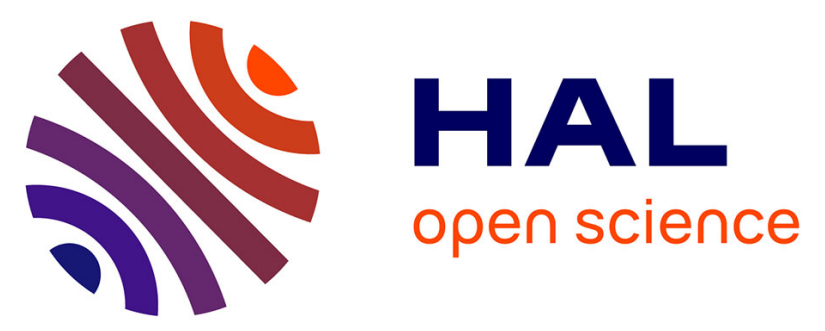

\title{
Study on Morphological Awareness and Rapid Automatized Naming Through Word Reading and Comprehension in Normal and Disabled Reading Arabic-Speaking Children
}

\author{
Smail Layes, Robert Lalonde, Mohamed Rebaï
}

\section{To cite this version:}

Smail Layes, Robert Lalonde, Mohamed Rebaï. Study on Morphological Awareness and Rapid Automatized Naming Through Word Reading and Comprehension in Normal and Disabled Reading Arabic-Speaking Children. Reading and Writing Quarterly, 2017, 33 (2), pp.123-140. 10.1080/10573569.2015.1105763 . hal-03220056

\section{HAL Id: hal-03220056 \\ https://hal.univ-lorraine.fr/hal-03220056}

Submitted on 6 May 2021

HAL is a multi-disciplinary open access archive for the deposit and dissemination of scientific research documents, whether they are published or not. The documents may come from teaching and research institutions in France or abroad, or from public or private research centers.
L'archive ouverte pluridisciplinaire HAL, est destinée au dépôt et à la diffusion de documents scientifiques de niveau recherche, publiés ou non, émanant des établissements d'enseignement et de recherche français ou étrangers, des laboratoires publics ou privés. 


\title{
Study on morphological awareness and rapid automatized naming through word
} reading and comprehension in normal and disabled Arabic-speaking children

\begin{abstract}
This study explored the role and extent of the involvement of morphological awareness in contrast to rapid automatized naming (RAN) in word reading and comprehension of Arabic as a morphological-based orthography. Measures of word reading, reading comprehension, morphological awareness, and RAN in addition to a nonverbal mental ability test were given to three groups of readers: a group with dyslexia $(n=20)$ from the $6^{\text {th }}$ grade compared to a group of normal readers matched in age $(n=20)$ and a younger reader group from the $4^{\text {th }}$ grade $(n=18)$. Thus, a potential age effect, besides the effect of a group factor, could be verified on morphological awareness and RAN, since the development of these two skills was reported to be substantially influenced by age in consistent orthographies. Results indicated that RAN was a significant predictor of word reading and reading comprehension while morphological awareness explained the variance only in reading comprehension. We conclude that rapid automatized naming and morphological awareness have important roles in predicting reading skills, and we suggest that it should be included more frequently in assessments and instruction.
\end{abstract}

Key words: Reading disability, word recognition, reading comprehension, morphological awareness, rapid automatized naming. 


\section{Introduction}

Morphological awareness (MA) and rapid automatized naming (RAN) deficits represent the best elements distinguishing dyslexic from non-dyslexic children at age 7 , considered strong correlates of developmental dyslexia (Hua Shu \& Hong Li, 2012). MA acknowledged as an important factor in word reading across alphabetic languages (Carlisle, 1995; Carlisle, McBrideChang, Nagy, \& Nunes, 2010; McBride-Chang, Shu, Zhou, Wat, \& Wagner, 2003; Wagner et al., 1997). However, its importance is thought to vary across orthographies (Deacon, Wade-Woolley, \& Kirby, 2007). Although evidence accumulated in the last few years converges on the importance of MA in learning to read in Arabic (e.g., Abu Rabia, 2012; Saiegh-Haddad \& Geva 2008), its functioning in regard to RAN has not yet been delineated (Abu Rabia, 2012). Little is known about RAN and reading comprehension (RC) among Arabic children (Abu-Rabia, Share \& Mansour, 2003; Abu-Rabia \& Awad, 2004). The purpose of this study was to explore the relationship between MA, RAN, and RC as well as the respective role of MA and RAN as predictors in word recognition and $\mathrm{RC}$ among normal and dyslexic Arabic speakers.

\section{The interplay among morphological awareness, word reading and reading comprehension}

MA, the ability to reflect on and manipulate the smaller meaningful units that form words (Kuo \& Anderson, 2006), is a basic skill with a strong influence on reading processes (Casalis \& Louis-Alexandre, 2000). MA involves the ability to identify word roots and their inflected or derived forms to understand the structure and meaning of a word and the different combinations of its morphemes. Accordingly, it refers to a conscious awareness of word structure and semantics while processing inflectional and derivational representations (Kieffer \& Lesaux, 2008). It represents one of the best discriminators of children with or without dyslexia (Shu, McBrideChang, Wu \& Liu, 2006) and contributes to a variety of literacy skills (Green, 2009).

Many researchers point out that MA is related to children's RC (Carlisle, 1995; 2000; Kuo \& Anderson, 2006; Singson, Mahony \& Mann, 2000) at different grade levels (Carlisle \& Fleming, 2003) as a function of exposure to unfamiliar words (Kuo \& Anderson, 2006). Carlisle (2000) showed that the awareness of morphological structures was significant for grade 2 children and stronger for higher grades. In a longitudinal study of French-speaking children, Casalis and LouisAlexandre (2000) found that MA accounted for variance in RC after controlling for IQ and vocabulary. Furthermore, Kieffer and Lesaux (2008) showed that awareness of derivational morphology played an increasingly important role in $\mathrm{RC}$. 
Researchers have argued that the contribution of MA to RC occurs via several possible paths (Deacon \& Kirby, 2004; Nagy, Berninger \& Abbott, 2006). It may happen depending on indirect mechanisms by facilitating the development of a wide vocabulary, which in turn promotes successful $\mathrm{RC}$ as well as in the accurate and rapid reading of words, which may release attentional resources for comprehension and enables individuals to analyze the internal structure of words and decode them more quickly and accurately. A second possible way follows straight mechanisms in making a direct involvement in the reading process by facilitating the extraction of semantic information from morphologically complex words.

Findings from Arabic studies (Abu Rabia, 2012) indicate that dyslexic readers rely on roots as well as short vowelization in reading to compensate for poor phonological decoding through reliance on a root identification strategy. The most significant differences between reading disabled children in grade 5 and control groups matched by chronological age and reading level were found in morphological tasks (Abu-Rabia, Share, \& Mansour, 2003; Ben-Dror, Frost, \& Bentin, 1995). These findings enhance the argument that Arabic readers rely on roots of words as key morphological entities to the initial lexical access in reading. Taken together, the empirical evidence of studies reviewed above indicates that the importance of MA to decoding and RC increases with age and contributes to RC (Nagy et al., 2006).

\section{The varying role of morphological awareness in reading across orthographies}

Many researchers have acknowledged the multiple roles of MA in reading words and RC (Georgiou, Parrila \& Papadopoulos, 2008, Lei et al, 2010; Tong, Deacon, Kirby, Cain, Parrila, 2011) and there is increasing evidence that the impact of morphology deficits in reading disability manifests itself differently across orthographies. Nagy, Berninger, Abbott, Vaughan and Vermeulen (2003) found varying roles of morphology in RC, which may be due to differences in

the orthographies studied. Accordingly, it has been suggested that the relevance of MA to reading depends on "morphological transparency", the relative degree to which the phonological structure of written words may be reliably recovered from their morphological structure (Saiegh-Haddad \& Geva, 2008). Thus, MA should be more relevant to reading in a language with a linear transparent morphological structure such as English than in a language with a non-linear one such as Arabic. Researchers argue that the morphology of the language plays an essential role in reading Arabic and Hebrew (Abu-Rabia, 2001; Abu-Rabia et al., 2003; Prunet, Béland, \& Idrissi, 2000; Shimron, 1999). 
Arabic morphology is mainly derivational, while others are concatenative. In derivational morphology, almost all words are derived from roots by applying patterns (Al-Sughaiyer \& AlKharashi, 2004). The words are based on phonological patterns built on roots that are consonantal. The root is usually made of three consonants and carries the core meaning of the words derived from it. For example, the word / jalis / ("seated") is made of the root consonants $\{\mathrm{s}, \mathrm{t}, \mathrm{d}\}$, which bears the meaning of "posture" and the pattern $\{\mathrm{CaaCiC}\}$ represents the active voice. Thus, derived Arabic words are composed of two abstract morphemes, the consonantal root, and the pattern, which results in words only after their combination and may involve the application of phonological rules. Therefore, Arabic can be considered as predominantly based on consonantal roots.

In contrast to the derivational process in which the basic components are roots and word patterns, the inflectional morphological system in Arabic is constructed by attaching prefixes and suffixes to words. Various vowels, prefixes, and suffixes are used with the root letters to create the desired inflection of meaning. Although Arabic morphology is not transparent in a non-vowelized form (i.e., short vowel diacritics), readers are likely to rely on visual recognition of the root and the pattern to support word recognition and the determination of meaning. The combination of morphological units in Arabic is not linear such that it relies on interlacing between the root and the word pattern which can be built of prefixes, suffixes, and infixes and intertwining with the root can affect the order of the root letters (Feldman \& Bentin, 1994). Therefore, the order of root letters depends on the word pattern and its interaction with the root for given grammatical information expressions. Example of constructing an Arabic word stem using the root and scheme: Root: / أ ت ت بtb" "ktb" Scheme: / تفاعل/ "tafaala" Stem: "takataba" / تكاتب/

\section{The role of rapid automatized naming in word recognition and reading comprehension}

RAN represents one of the most powerful predictors in the reading ability of children across orthographies, both in transparent (Brizzolara et al., 2006; Mann \& Wimmer, 2002) and opaque (Parrila, Kirby \& McQuarrie, 2004; Roman, Kirby, Parrila, Wade-Woolley \& Deacon, 2009) orthographies. In different languages, RAN was a significant predictor of reading in typically developing and reading-impaired populations (e.g. Georgiou, Das \& Hayward. 2008 ; Georgiou, Parrila \& Papadopoulos, 2008; Furnes \& Samuelsson, 2010; Vaessen et al. 2010). More importantly, the strength of prediction of RAN varies in regard to the depth of language 
orthography (Vaessen et al., 2010). However, the prediction pattern of RAN showed divergent findings in Arabic based studies. Saiegh-Haddad (2005) demonstrated that although RAN was significantly associated with all literacy measures in grade 2 children, it failed to predict variability in literacy independently of phonological awareness (PA). More recently, rapid naming (measured by the Stroop test) did not appear as an independent predictor (Al Mannai \& Everatt, 2005), diverging from findings in other transparent orthographies (i.e. German). Such controversy among Arabic based studies may be related to the nature of the instrument by which RAN is measured. RAN assessed by three different tasks predicted word reading in the $4^{\text {th }}$ and $5^{\text {th }}$ grades of dyslexic and normal readers (Layes et al., 2015b à vérifier est-ce $\mathbf{O K}$ ?). RAN was more closely associated with reading fluency, whereas the phonological measure was linked to accuracy and comprehension, supporting recent findings reported by Wolff (2014), who demonstrated that RAN predicts reading speed whereas PA predicts RC in examining longitudinal data from a reading intervention study carried out for 9-year-old children with reading difficulties.

In sum, performance on RAN tasks (objects, letters, digits) have been shown to be strongly correlated with RC (Powell, Stainthorp, Stuart, Garwood, \& Quinlan, 2007) and it is thought to facilitate RC because it releases resources for meaning in the comprehension process (Verhoeven \& Perfetti, 2008). However, it is hard to find any Arabic study that has explicitly investigated multivariate relationships by which direct contributions of MA and RAN are assessed on word recognition and $\mathrm{RC}$, though Arabic is a morphologically based orthography.

\section{Review of the Arabic based literature}

Previous Arabic based studies (Abu Rabia, 2003, 2007, 2012) showed that morphology, via identification and production tasks, was the most powerful predictor of both reading accuracy and RC among dyslexic and normal readers across grades 3, 6, 9, and 12 . The dyslexics and the two control groups (matched for age and reading level) performed better on vowelized compared to unvowelized reading measures except for morphology (Abu Rabia, 2012). It seems that full vowelization played a facilitating role in reading achievement and therefore an unvowelized version of stimuli (absence of diacritics) would make it more difficult. Furthermore, findings of Abu Rabia (2012) show varied effects of full vowelization on pseudo-words and reading tasks. Accordingly, it seems appropriate to investigate the role of morphology in a neutral phonological condition where consonants are partially vowelized. Consistent with this aim, the present research focused on partially vowelized items. 
Conversely, recent findings provided by Taha (2013) showed that there is no significant correlation between MA and the processes of reading and decoding. This may be related to the nature of the morphological test relying on the deduction of semantic relations between words rather than pure MA. This lack in the sensitivity of the tests used may have led to assessing MA performance inadequately. We proposed five morphological tasks, including recognition, judgment of relatedness, and production skills. Additionally, it is hard to find in the Arabic literature a study in which RC was studied along with MA and RAN. In Mahfoudhi, Elbeheri, Everatt \& Al-Rashidi (2010), besides MA and RAN, RC studied among children with literacy and mathematics learning difficulties (LD) was limited to the measurement of speed of implementation (fluency). More recently, MA and RAN were associated with reading accuracy (Taha, 2013).

The specific issue addressed in this study was to determine whether there is an influence of MA and RAN on reading words and RC of dyslexic as well as age-matched and younger normal readers in grade 4 . Comparisons between dyslexics and age-matched controls are of great interest to identify the diagnosis-specific characteristics of children with dyslexia as well as identifying factors underlying poor reading. Furthermore, the discrepancy by grade in reading-related skills by comparisons with younger children (grade 4) is relevant to reading development. Differential performance patterns, according to which the dyslexic group show deficits relative to a younger group on some measures would indicate that disabled readers are not just slow developers but have special characteristics.

\section{The present study}

It is argued that in alphabetic languages, MA was the best predictor of reading accuracy and RAN of reading speed (Kirby et al, 2012; Snowling \& Hulme , 2012). Studies suggested that morphological processing has a great importance regarding controlling processes in reading Arabic orthography (Abu-Rabia, 2007; Abu-Rabia \& Taha, 2005; Taha, 2013; Taha, Ibrahim, \& Khateb, 2013). Accordingly, it is important to investigate the contribution of different cognitive and metalinguistic skills in reading Arabic among typical and poor readers, due to the morphological richness of the Arabic language, and to examine the best predictors in reading efficiency, particularly in RC, which may contribute in the elaboration of assessment tools for Arabic children, as previous studies suggest that MA should be a more standard component of early assessment batteries (Bowers, Kirby, \& Deacon, 2010 ; Nunes \& Bryant, 2006). 
Arabic disabled readers may be able to rely on phonological information provided by voyelisation signs (diacritics) to overcoming morphological processing difficulties. This reliance on phonological information may differ in the two reading tasks, namely word decoding and RC. Because of the relationship between phonological processing and MA detailed in the literature, these two areas of processing were contrasted to ensure that any influence of MA was not due to its relationship with phonological processing and the latter's influence on RC. The present study examined the relationships between MA and RAN as independent variables as well as word recognition and $\mathrm{RC}$ and the respective contributions of each to the prediction of reading words and comprehension among typically developing and dyslexic Arabic children in the $4^{\text {th }}$ and $6^{\text {th }}$ primary grades.

Based on issues raised above, the questions that the present study aims to answer are specified as follows:

a) - How do dyslexic children compared to controls perform on RC, MA, and RAN as main related reading skills?

b) - Is there a significant group effect (dyslexics vs. normal readers) and/or grade effect ( $4^{\text {th }}$ vs. $6^{\text {th }}$ grade) on RC, MA, and RAN?

b) - What is the extent of the prediction pattern of word recognition and $\mathrm{RC}$ from these readingrelated variables (MA and RAN)?

It was anticipated that the dyslexic group would perform less well than age-matched control and younger groups in basic reading tasks (phonological processing measured by pseudoword identification and word recognition), RC, RAN and MA. These differences would also be exhibited between normal readers of $4^{\text {th }}$ and $6^{\text {th }}$ grades after controlling for the group variable, and therefore, would indicate for each factor a unique contribution to reading words and RC.

Given the level of morphemic consistency and the apparent importance of morphemes (outlined above) in the Arabic language, MA was expected to have a strong influence on reading Arabic and, hence, explains variability in word recognition and RC. Since RAN was a powerful predictor in several transparent orthographies, we expected RAN to be strongly related to RC and word reading in Arabic speaking children.

\section{Method}

\section{Participants}

Three groups of readers were screened in their school. In total, 40 students from grade 6 were diagnosed on the basis of their performance on a literacy test (Layes et al.,2015a,b je crois 
que c'est ceci et non 2014, 2015). The dyslexic group $(n=20)$ was composed of 6 females and 14 males, their mean chronological age was 133.60 months $(\mathrm{SD}=8.37)$. As additional criterion for the group of dyslexics was their performance on general ability showing adequate performance on the Raven Standardized Matrices test compared to controls (Table 1). The age-matched group $(n=20)$ was composed of 5 females and 15 males and their mean age in months $130.09(\mathrm{SD}=$ 3.99). However, the initial number of age-matched control (AC) group ( $n=23)$ was reduced after removing outlier scores. A younger normal reader group $(n=18)$ was included from grade 4 , their mean age being 116.83 months $(\mathrm{SD}=5.12)$. This group was included as a reading level control planned in three groups (dyslexics, aged matched and reading level matched groups). However, unpredictably we got a normal reader group younger than the dyslexic group (- 2 years) but with a higher reading level (significantly superior reading scores), so a reading matched controlling factor was not conductible. However, we maintained data of this younger reader group to investigate potential differences within normal readers differentiated according to grade (grade 4 vs. grade 6), which would indicate a significant role of age/instruction in related reading skills.

\section{Materials and procedure}

\section{Literacy tasks}

This test was elaborated beforehand for the purpose of reading assessment skills in children 9-11 ages (Layes, et al., 2014, 2015 Layes, et al., 2014, 2015a,b ?). A set of 80 stimuli was given (40 frequent words and 40 infrequent words). The words used varied for length (bisyllabic and disyllabic) and frequency (high and low); in addition to a list of 20 pseudo-words varied for orthographic length. Participants were required to read the stimuli aloud. The number of correct responses (accuracy) and reading speed (time in sec per list) were scored. The two word types were further categorized as high or low frequency. Frequency was determined by asking the Aralex lexical database for Modern Standard Arabic (Boudelaa \& Marslen-Wislon, 2010). All frequent words contained more than 25 appearances per million.

1. Single words reading test $(\alpha=.88$, inter consistency coefficient).

Participants read 80 partially vowelized words, 40 words matched for frequency (40 frequent / 40 infrequent). Each list was presented on a white sheet of A4 paper. Participants were required to read aloud the item correctly without any limitation in time. The score for this test was based on the total number of words correctly read.

- Frequent word reading 
The stimuli consisted of two lists of 40 words: 20 simple words and 20 complex words. According to their internal graphemic structure, words were considered to be simple and complex depending on whether letters were totally or partially legated (graphically connected).

\section{-Infrequent word reading}

Two lists of 40 words included 20 simple words and 20 complex words, based on the same characteristics as the previous task. The score of total words read was defined as reading frequent words and infrequent words.

\section{Phonological processing: Pseudo words identification task $(\alpha=.83)$.}

Pseudo-word identification is a trustworthy measure of phonological coding and graphemeto-phoneme decoding skills (Pugh et al., 2012) and represents the most commonly used task in transparent systems (Abu Rabia \& Abu-Rahmoun, 2012; Jiménez \& Ramírez, 2002). This task consisted of a list of 20 partial vowelized pseudo-words varied for orthographic length (CVCV /CVCVC). Items were not rooted from Arabic real words which may introduce a frequency effect in the identification performance (Layes et al, in preparation) .

\section{Reading Comprehension}

This test is an adapted version of a reading comprehension subtest labeled "sentence comprehension" of Khomsi's LMC-R test (1999), composed of 15 items. The sentences were in some way designed in ascending order of syntactic difficulty (structural length). Reading comprehension includes sentences along with pictures. Children silently read a sentence and selected the target picture from four choices best representing the sentence without limitation of time. The other pictures were distracters that included only some information of the sentence. This reliance on pictures as a source for extracting meaning parallels RC instructions received at primary school. In this context, it should be noticed that the use of oral questions (rather than pictures) involves an additional linguistic load, with may constrain reading comprehension in poor reading children, known to have poor listening comprehension (Nation, 2005), regarding the strong relationship between written and spoken language comprehension. In addition, using a longer connected text may involve supplementary cognitive skills, particularly working memory, weak in dyslexics. Hence, we should consider that our reading comprehension assessment uses short sentences, without demanding much working memory relative to reading passages or paragraphs. That condition might have facilitated dyslexic performance, and we think that in longer texts, the overload of working memory can impair their RC measures.

\section{Morphological Awareness test}


This measure was adapted from an Arabic MA version elaborated by Taha and SaieghHaddad (submitted), which assesses a child's implicit morphological awareness knowledge. All words were partially vowelized (phonologically transparent). We paid attention (for all subtests) that the selected words are known to children. A score of (0) was given for incorrect or partially correct responses and (1) for correct responses. The students were given two practice items before the task was initiated. The examiner recorded whether each item was correct or incorrect. The score was the number of correct responses. For this study, the alpha reliability was .78. The internal consistency reliability coefficient was adequate (Alpha Cronbach $=.86)$. It consisted of five tasks:

- Morphological Judgment Relationship task

The purpose of this subtest was to evaluate the knowledge of (derivational) morphology which refers to the child's ability to recognize the morphological relationship (relational knowledge) between words. Pairs of words related either morphologically (e.g. 3amal [work] /3amel/ [worker]) or semantically (e.g. mahkama [tribunal] / 3adala [justice]) were presented to the children, who decided whether the two words belonged or not to the same morphological family. This type of task is widespread in morphological awareness assessment (Mahony, Singson and Mann, 2000; Nagy et al , 2003; Nagy et al, 2006).

A set of 20 word pairs of words was used, frequent in stem and derived forms. The examiner presented 20 pairs orally one by one. The child was given these instructions: You will hear pairs of words that sound alike. Listen carefully and tell me whether the words that I say are from the same family or not." The child responded yes if the word pair was morphologically related and no if the word pair was morphologically unrelated. Some of the pairs were semantically but not morphologically related, which might provide an ambiguous sight for the examinee. Two pairs of high-frequency words, of stem or derived form, were presented as practice items. Two additional trials were provided if the child experienced difficulty understanding the task.

\section{- $\quad$ Morphological Production task}

This task was conceived to examine the participants' ability to generate a number of words morphologically related to the original given one's route. Ten words (verbs) partially vowelized were presented to the participant instructed to generate four derived forms for each word in five minutes. Because of the time limit, each participant was solicited to perform as fast as possible. The expected responses follow various patterns commonly used in Arabic: agentive (e.g., ka:teb 
[writer]), passive adjective (e.g., maktu:b [written]), place adverbial (e.g., maktab [office]), and reciprocal verbal (e.g., ka:taba [corresponded])

- Pattern Recognition task

Participants were asked to decide whether the two words presented orally have (or not) the same pattern (e.g. CvCCaCa). Example:/ mighsala / [Laundry] and /mazra3a/ [Farm]. Participants responded by "yes" or "no".

- Morphological Dismantling task

This task measures the students' ability to analyze and break down complex words into smaller meanings. It is composed of 14 items. Participants were instructed to hear the items one at a time and segment them into meaningful parts, as many smaller meanings as they could identify in each item. It is worth noting that the instructions were followed directly with an example to illustrate what they should do with each item.

- Decision in accordance with the Ortho morphological format task

A list of four words in each sequence and frequent in stem and derived forms was used. They share the same pattern except one: agentive (e.g., ka:teb [writer]), passive adjective (e.g., maktu:b [written]), place adverbial (e.g., maktab [office]), and reciprocal verbal (e.g., ka:taba [wrote]) (Saiegh-Haddad \& Geva, 2008). Participants were instructed as follows: after reading every set of words, underline the word that is different from the rest of the words in terms of shape (pattern).

\section{Statistical analyses}

Multiple analysis of covariance (MANCOVA) was used to test group differences on all measures. Due to unexpected inequality in the IQ of the three groups as well as reading level between reading-disabled and younger normal readers at grade 4, the MANCOVA was conducted to test whether those differences remained after controlling for differences in IQ, age, and reading level (Abu rabia, Share and Mansour, 2003). To address our second aim corresponding to locate the source of variance, the Boneforri post hoc test was used. Furthermore, two separate hierarchical regression analyses were conducted to locate the most powerful predictors of both word reading and reading comprehension achievement for the entire sample.

\section{Results}

We examined whether RC, MA, and RAN distinguishes dyslexics from age-matched peers and normal younger readers and to inspect the extent to which MA and RAN as independent variables are related to word reading and RC. The Kolmogorov-Smirnov test of normality (as well 
as Shapiro-Wilk test) showed no significant values for RC, MA, and RAN for the two reader groups, in addition to the RC and IQ (all values $>.05$ ), indicating no violation of the assumption of normality. Although the homogeneity of variance assumption was not violated regarding Leven's test in total basic reading skill and MA, there were significant values for RC and RAN. However, a a between-subject ANOVA with an almost equal numbers of participants contributing to the mean does not usually lead to increasing chances of drawing false conclusions (Zar, 1996), especially when the skew for each means is in the same direction for each group.

Descriptive data by group, means and, standard deviations for each measure are shown in Table 1, presenting ANOVAs of the three groups on word recognition and RC, MA, and RAN. The results on Raven's standard progressive matrices indicate that the dyslexic group (grade 6) and the age-matched control were at the same level but higher than younger's mean IQ, likely due to the age difference between the two grades. D'après le tableau les dyslexiques sont equivalents aux jeunes et non aux vieux. La phrase serait alors : The results on Raven's standard progressive matrices indicate that the dyslexic group (grade 6) and the younger control were at the same level but higher than age-matched controls. As predicted, the children with dyslexia were impaired in basic literacy tasks, RC, total MA score, and total RAN score. In particular, children with dyslexia had lower values in five measures of MA and RAN (Object) tasks than both age-matched controls and younger readers. The word recognition results indicated significant differences between the three groups, while the reading-disabled generally performed less well than the other two non-dyslexic reading groups. The RC results mirrored the word recognition results. However, the unexpected differences in reading level between the reading-disabled and younger normal readers (grade 4) are treated statistically in the next section.

\section{Insert table. 1}

\section{The main effects of "Group" and "Grade"}

Two separate one-way multivariate analyses of covariance (MANCOVA) of the three grouped (dependent) variables (RC, MA and RAN) were implemented, alternatively for "grade" $\left(4^{\text {th }}\right.$ versus $6^{\text {th }}$ normal readers) and "group" (dyslexic versus controls) as fixed factors, and controlling for nonverbal ability and age. When the "grade" variable is entered as a fixed factor, "group" variable is entered as covariate. Variance-covariance matrices were compared between groups with Box's M-test giving a significant value, indicating that the homogeneity of covariance has not been met, so that Pillai's trace was taken as more robust to this violation instead Wilk's 
lambda and we can ignore this assumption when group sizes are almost equal (Leech, Barrett, \& Morgan, 2011). To go farther in the analysis, we performed a MANCOVA for MA and RAN separately taking subtests of each measure as dependent variables.

\section{Group effects}

MANCOVA with RC, MA and RAN as dependent variables and GROUP as the fixed factor was run. The omnibus effect for Group was significant (Pillai's $=.293, \mathrm{~F}_{(3.51)}=7.04, p<$ 0.000), partial eta squared $=.293$. Power to detect the effect was .972. Given the significance of the overall test, the univariate main effects were examined. Significant main effects on ANOVA were obtained for Reading Comprehension, $\mathrm{F}_{(1.53)}=15.934, \mathrm{p}<.000$, partial eta square $=.231$, power $=.795, \mathrm{MA}, \mathrm{F}_{(1.53)}=14.522, \mathrm{p}<.000$, partial eta square $=.215$, power $=.963$, and $\mathrm{RAN}, \mathrm{F}$ $(1.53)=9.337, \mathrm{p}<.004$, partial eta square $=.150$, power $=.851$.

Multivariate analysis of covariance for the MA tasks was implemented with GROUP as the fixed factor and controlling for nonverbal ability and grade level. Box's M-test of equality of covariance indicated that the homogeneity of covariance has not been met $(20.22>.05)$. The omnibus effect for group was significant (Wilks' $\lambda=.675, F_{(5.49)}=4.72, p<0.001$ ), partial eta squared $=.325$. Power to detect the effect was .963 . Given the significance of the overall test, univariate main effects were examined. Significant univariate main effects were obtained for two of the five subtests: Morphological Production, $F_{(1.53)}=14.18, \mathrm{p}<.000$, partial eta square $=.211$, power $=.959$; and Pattern Recognition, $F_{(1.53)}=11.47, \mathrm{p}<.001$, partial eta square $=.178$, power $=$ 914. Additionally, multivariate analyses of covariance for RAN subtests were performed with GROUP as the fixed factor and controlling for nonverbal ability and grade. Box's M-test of equality of covariance indicated that the homogeneity of covariance has not been met (10.98> .05). The omnibus effect for group was significant (Wilks' $\lambda=.818, F_{(3.51)}=3.79, p<0.01$ ), partial eta squared $=.182$. Power to detect the effect was .785 . Given the significance of the overall test, the univariate main effects were examined. Significant univariate main effect was obtained for one among the three subtests: RAN Objects, $F_{(1.53)}=10.60, \mathrm{p}<.002$, partial eta square $=.167$, power $=$ .892 .

\section{Insert figure 1}




\section{Grade level effects}

MANCOVA with grade level as the fixed factor was replicated for RC, MA and RAN as dependent variables and GRADE as the fixed factor. The omnibus effect for Grade was significant (Pillai's $=.239, \mathrm{~F}_{(3.52)}=5.44, p<0.002$ ), partial eta squared $=.239$. The observed power to detect the effect was .920. Given the significance of the overall test, univariate main effects were examined. Significant ANOVAs main effects were obtained for RC, $F_{(1.54)}=2.095, \mathrm{p}>.05$, MA F ${ }_{(1.54)}=5.687, \mathrm{p}<.05$, partial eta square $=.095$, power $=.649$, and RAN, $\mathrm{F}_{(1.54)}=1.427, \mathrm{p}>.05$. MANCOVA with "Grade level” as the fixed factor was replicated for MA tasks. Box's M-test indicated heterogeneity of covariance $(18.86>.05)$. The omnibus effect was significant (Wilks' $\lambda=$ $\left..710, F_{(5.49)}=3.99, p<0.004\right)$, partial eta squared $=.290$. Power to detect the effect was .925 .

Significant univariate main effects were obtained for the same subtests cited above: Morphological Production, $F_{(1.53)}=8.52, \mathrm{p}<.005$, partial eta square $=.138$, power $=.817$; and Pattern Recognition, $F_{(1.53)}=7.27, \mathrm{p}<.009$, partial eta square $=.121$, power $=.754$. Box's M-test of equality of covariance also indicated indicated heterogeneity of covariance for the three RAN substasks $(9.75>.05)$. The omnibus effect for Grade level was not significant (Wilks' $\lambda=.981, F_{(3.51)}=0.32$, $p>0.05)$. Subsequently, no significant univariate main effects were obtained.

As demonstrated in the MANCOVA outputs for RC, MA and RAN, there were significant effects of group and grade variables.

\section{Correlations and hierarchical regression analyses}

To examine the relationship between literacy, RC, RAN, and MA, intercorrelations are shown among all measures after partialling out the effects of age and IQ in Table 2 for each group of readers. A dissimilar profile was displayed for the two cohorts. In the dyslexic group, word reading was not associated with RC, MA, or RAN. In the normal reader group, word reading reading was strongly correlated with $\mathrm{RC}(\mathrm{p}<.01)$ and $\mathrm{RAN}(\mathrm{p}<.000)$. Pseudo-word identification correlated with all measures $(\mathrm{p}<.05)$ only in the normal group only. RC and MA were significantly associated $(\mathrm{p}<.01)$ as well in both groups of readers, but no correlation was found between RC and RAN.

In summary, the analysis suggests that efficiency for both word recognition and RC relies mainly on phonological processing and MA in the normal development of reading skills.

\section{Insert table 2}


Hierarchical multiple regressions were performed on combined data from the three groups to examine the extent to which phonological processing, MA, and RAN explained variability in word reading and $\mathrm{RC}$. The control variables for age and IQ were entered as the first block into each regression analysis. The meta-linguistic measures were entered with phonological processing first because it is best established as a strong correlate of reading skills. RAN and MA were second and third because they have been shown to be less strongly related to literacy (e.g., McBrideChang et al, 2010), and finally RC was taken as an independent variable for word reading outcome and vice versa. MA and RAN, and phonological processing were then entered in the second, third and fourth blocks, respectively.

As shown in Table 3, regression analysis indicates that two of the four variables explained word reading ability: age and IQ $\left(R^{2}=0.20\right)$; pseudo-word identification variance explained $=0.19$. However, $\mathrm{RC}$ as the dependent variable was moderately to strongly predicted by all independent variables: age and IQ $\left(R^{2}=0.44\right)$, pseudo-word identification $\left(R^{2}=0.10\right)$, RAN $\left(R^{2}=0.14\right)$, and MA $\left(R^{2}=0.06\right)$. Overall, the four metalinguistic skills were more associated with $\mathrm{RC}$ than word reading.

\section{Insert table 3}

\section{Discussion}

As expected, significant differences appeared between dyslexics and two normal reader groups on word reading, RC, MA, and RAN. Post-hoc comparison in MA showed that on average age-matched controls performed better than dyslexics and younger readers, who were comparable with dyslexics; however, in the RAN test, although dyslexics were poorer than age-matched controls, they performed equally with younger controls. The significant differences between normal reader groups and dyslexics in the two morphological tasks demonstrate the importance of morphological knowledge on reading skills, which may increase as reading experience evolves (Carlisle, 2000; Singson et al., 2000). These results are comparable with those showing impairments in reading comprehension among Arabic dyslexics (Abou rabia, 2002, 2007; Mahfoudhi et al, 2010; Saiegh-Haddad \& Geva, 2008), suggesting that children with dyslexia have difficulty in decoding the written words that affect comprehension. 
Dyslexic children had lower scores on two of five MA tasks, namely Morphological Production and Pattern Recognition, leading to significant difference in the total score of MA between groups. A similar result was reported by Abu-Rabia et al (2003), where the performance of the readingdisabled children in morphological tests (Morphological relatedness and Morphological derivation) was significantly poorer than that of the other groups (age-matched and younger readers groups). Similar findings have also been presented in Hebrew (Ben-Dror et al., 1995), demonstrating that morphology is a key variable in reading Semitic languages. During reading, MA may facilitate the accurate recognition of words in sentences (Nagy, Berninger \& Abbott, 2006). If individuals are more readily able to recognize word parts, they are likely to recognize both the word and its meaning, since morphemes represent both orthography and meaning. Such status is more acknowledged in Arabic as non-concatenative language, which uses both linear and non-linear morphological processes and employs two types of bound morphemes: a consonantal root, which carries the semantic core (meaning) of the word (e.g., KTB) and a word pattern or vowel template, which, together with the consonantal root, form a word (e.g., KaTaBa) (to write). These characteristics add to the challenge of learning to read in Arabic.

Our findings demonstrating a strong relation between decoding (words and pseudo-words) and $\mathrm{RC}$ in the non-dyslexic cohort, but not in the dyslexic one, are in agreement with previous ones, indicating that MA may contribute to text comprehension by supporting the interpretation of unknown words (Carlisle, 2000; Nagy et al., 2006). This complies with the "Simple View of Reading” (SVR) (Gough \& Tunmer 1986; Hoover \& Gough, 1990), which suggests that RC results from developing skills in the areas of decoding and linguistic comprehension, and hence contributes significantly to reading skills in young children (de Jong \& Van der Leij, 2002). However, RC can be impaired when only one of the two abilities is poor. The strong correlation between MA and RC in both groups of readers may be described in the framework of the SVR model. That is to say, all subtasks in our MA test require oral language comprehension, as instructions and items were orally presented to participants. This might explain why MA serves as a predictor of $\mathrm{RC}$ but not in word reading.

Dyslexic readers with difficulties in MA are likely to have difficulties in identifying and discriminating morphemes, manipulating the morphemic structure, and generalizing morpheme meaning. They may be unaware of the role of roots and flexional derivational relations. Thus, poor MA may unable dyslexics to form clear semantic representations of morphemes which could lead to a potential problem in reading development. In addition, results showed that word recognition, 
pseudo-word pseudo-word identification, and RC were significantly correlated with MA and RAN in typical readers, findings consistent with previous ones conducted in relatively transparent orthographies and children of comparable age, indicating that rapid naming is associated with reading skills across ages (e.g., Kirby, Georgiou, Martinussen, \& Parrila, 2010 ; Vaessen \& Blomert, 2010). RAN appears to be related to word reading, as both tasks require serial processing and activation of naming processes. However, RAN seems to be more related to RC (reading sentences) than word reading, underlying the probable major role of semantic processing speed (serial character) required in both tasks which facilitate fluency of implementation.

Current findings revealing strong relations between MA and RC in children's elementary grades corroborate previous Arabic ones (Abu Rabia et al, 2003; Taha, 2013), suggesting that MA actually contributes to RC (Carlisle, 2000; Nagy et al., 2006; Siegel, 2008), and this contribution seems to be increase with age in morphology production, as demonstrated by differences between normal readers of grade 4 and grades 6 (e.g. Kuo \& Anderson, 2006). Furthermore, such strong associations between MA and $\mathrm{RC}$ indicate that awareness in the morphemic structure of words could guide children's understanding of novel morphologically complex words. This might, in turn, facilitate text comprehension. Conversely, children with weak MA may not be able to process proficiently the morphemic structure of complex words, causing difficulties in reading comprehension (Tong et al, 2011).

Our results also indicate that morphology measures explained significant levels of variability in RC scores, in addition to that predicted by RAN, nonverbal ability, and grade level. Indeed, these data suggest that in comparison with each other, RAN and morphological ability explain unique, independent variability in comprehension levels in this Arabic-speaking cohort of children. In contrast, there was no evidence that morphology measures were predictive of better word reading. The association between MA and RC suggests that students' ability to reflect on and manipulate the smaller meaningful units that form words is crucial to access semantics (Deacon \& Kirby, 2004; Nagy et al, 2006). Hence, our findings provide further empirical evidence demonstrating that the role of MA in children's reading development increases in later elementary grades because of an increasing number of complex words to which they are exposed in written form (Wolter, Wood, \& D’zatko, 2009).

As expected, the performance of the reading-disabled children in RAN was significantly poorer than that of normal readers. These findings accord with previous ones demonstrating the role of RAN as a predictor of reading abilities in children learning transparent languages 
(Georgiou et al, 2008; Landerl \& Wimmer, 2008) and that RAN may be a better predictor of reading development in consistent than in inconsistent orthographies.

RAN was negatively correlated with both RC and reading rate (Arnell, Joanisse, Klein, Busseri, \& Tannock, 2009). These findings are broadly consistent with the view that rapid naming problems are one of the main characteristics of dyslexic children learning a transparent orthography. One hypothetical explanation for the relation in normal readers is that RAN expresses orthographic processing. An efficient access to the orthographic lexicon depends on the accurate integration of visual information about letter sequences in words. Delayed identification may hinder the storage of representations of orthographic patterns (i.e., whole words) (Bowers \& Newby-Clark, 2002; Conrad \& Levy, 2007).

Beyond seriality, RAN is related to reading because it requires pronunciation of specific names which may depend on phonological processing and facilitate lexical access in normal readers (Georgiou, Parrila, Cui \& Papadopoulos 2013), as demonstrated by the correlation between pseudo-word identification and RAN. However, dyslexic children seem more reliant on MA on the basis of the association between this variable and RAN, as compensation of the phonological deficit, but it may slow down the automatic processing of extraction and induction of orthographic patterns.

Surprisingly, RAN showed no association with reading in dyslexics. This finding is somewhat consistent with Torgesen, Wagner, \& Rashotte (1994), who reported that the unique and significant contribution of RAN to reading disappears after grade 3. A moderate to insignificant correlation was also found by Landerl et al. (2012) across European orthographies. This lack of relationship may be explained by the sequential characteristic of naming items, particularly in alphanumeric RAN tasks (letters, digits) (Ziegler, Pech-George, Dufau, \& Grainger, 2010). Timed serial identification tasks across modalities appear to be consistently difficult for individuals with dyslexia (Ramus \& Ahissar, 2012). However, RAN tasks differ in predicting literacy. While RAN Objects contributed more significantly in predicting reading comprehension (coefficient of Final Beta), RAN Digits and Shapes did not. On the contrary, RAN tasks were not predictive of reading words, which agrees with data published by Maya, Katzir, Wolf \& Poldrack (2004), who asserted that color and object RAN are not predictors of reading performance in normal readers after the first or second grade, but that letter and digit RAN continue to predict performance in normal readers until the age of 18 , suggesting that the better predictive characteristic of letters and digits are due to fact that good readers automatize letter and digit naming after grade 1, whereas poor 
readers do not. Furthermore, our finding of RAN deficits in dyslexics support cumulating data indicating the presence of a second core deficit in dyslexia indexed by naming-speed (Wolf, 1997, 1999; Wolf \& Bowers, 1999; Wolf, Bowers, \& Biddle, 2000) and/or speed of processing deficits (Breznitz, 2001) manifested in later fluency and comprehension problems.

\section{Practical implications}

The findings of the present study may contribute to the formal standardization of measures used to improve assessment procedures among Arabic speakers. This field of research would benefit from the development of standardized measures of MA with higher levels of reliability. The most important practical aspect is the relation between MA, RAN, and reading abilities. There is an important need to include explicit instructions on morphological knowledge starting from initial grades of reading acquisition. Promoting students' morphological knowledge predicates their academic success (Beck, McKeown \& Kucan, 2002). As MA and RAN do not require reading, it may be advantageous that special diagnostic tools include MA and RAN.

\section{Limitations and suggested studies}

Several limitations need to be noted including the small sample size, which may have prevented us from detecting subtler differences in reading profiles. Another reason for caution in interpreting our findings is the use of a single measure of RC, the LMC-R test, in which children point to one among four pictures corresponding to the sentence. This task has not been used in other Arabic studies, and so futher empirical studies are needed to validate such an instrument with reasonable reliability.

Although control groups were designed in the research procedure, our three groups were imperfectly matched on word reading accuracy, indicating an overlap of age/reading level sampling, reducing the potential impact of word reading on our results. Further studies designed with two control groups (age-matched and reading level-matched) may maintain at least 3 years in chronological age to ensure the control of reading levels. Future research using experimental and longitudinal data is needed to investigate such reciprocal or recursive developmental processes. Similarly, larger sample sizes within each grade would have provided greater power to detect differences related to grade level.

The Morphological production task, a writing-based task, might have yielded different results than an oral version. Future studies should consider using the oral version because of the 
lack in writing efficiency in dyslexics. Tasks with insignificant outcomes between groups in MA and RAN should be changed. As evidenced from the importance of MA on reading achievement, we need to test empirically the impact of training on MA and improving unexpectedly poor readers. Longitudinal studies have much to contribute to current educational practice, particularly when taken in light of such intervention studies.

\section{Conclusions}

In the present study, MA was an important discriminator between good and disabled readers, supporting a growing body of research emphasizing the crucial role of this variable, particularly awareness of derivational morphology, in skilled but also in poor readers. This provides empirical evidence of the importance of $\mathrm{MA}$ in decoding and $\mathrm{RC}$ as a function of age in Arabic and other orthographies. It should be noted that our findings can only inform the reader about associations among independent variables (MA and RAN) and dependent variables (decoding abilities and RC), not about causal relations. Thus, strong word identification and reading fluency are necessary but not sufficient for RC. A causal relation between the variables needs to be verified via intervention strategies aimed at assessing reading skills before and after direct instructions on the components of MA.

\section{References}

Abu-Rabia, S. (1995). Reading in Arabic orthography: Phonological, syntactic, working memory skills in normally achieving and poor Arabic readers. Reading Psychology: An International Quarterly, 16(4), 351-394.

Abu-Rabia, S. (2001). The role of vowels in reading Semitic scripts: Data from Arabic and Hebrew. Reading and Writing: An Interdisciplinary Journal, 14, 39-59.

Abu-Rabia, S. ( 2007). The role of morphology and short vowelization in reading Arabic among normal and dyslexic readers in Grades 3, 6, 9, and 12. Journal of Psycholinguistic Research, 36, 89-106.

Abu-Rabia, S. (2012). The role of morphology and short vowellisation in reading morphological complex words in Arabic: Evidence for the domination of the morpheme/root-based theory in reading Arabic. Creative Education, 3 (4), 486-494.

Abu-Rabia, S., \& Awwad, Y. (2004). Morphological structures in visual word recognition: The case of Arabic. Journal of Research in Reading, 27, 321-336

Abu Rabia, S., Share, D., \& Mansour, S. M. (2003). Word recognition and basic cognitive processes among reading-disabled and normal readers of Arabic. Reading and Writing: An Interdisciplinary Journal, 16, 423-442.

Al Mannai, H., \& Everatt, J. (2005). Ponological processing skills as preditors of literacy amongst Arabic speaking Bahraini children. Dyslexia: An International Journal of Research and Practice, 11, 269291.

Al-Sughaiyer ,I., \& Al-Kharashi, I. A. (2004). Arabic Morphological Analysis Techniques: A 
Comprehensive Survey. Journal Of The American Society For Information Science And

Technology, 55(3),189-213,

Arnell, K. M. Joanisse, M. F., Klein, R. S., Busseri, M. \& Tannock, R. (2009). Decomposing the relation between Rapid Automatized Naming (RAN) and reading ability. Canadian Journal of Experimental Psychology, 63, 173-184

Beck, I., McKeown, M., \& Kucan, L. (2002). Bringing words to life: Robust vocabulary instruction. New York: Guilford.

Ben-Dror, I., Frost, R., \& Bentin, S. (1995). Orthographic representation and phonemic segmentation in skilled readers: A cross-language comparison. Psychological Science, 6, 176-81.

Boudelaa, S., \& Marslen-Wilson, W. D. (2010). ARALEX: A lexical database for Modern Standard Arabic. Behavior Research Methods, 42, 481-487.

Bowers, P. N., Kirby, J. R., \& Deacon, S. H. (2010). The effects of morphological instruction on literacy skills: A systematic review of the literature. Review of Educational Research, 80, 144-179.

Bowers, P. G., \& Newby-Clark, E. (2002). The role of naming speed within a model of reading acquisition. Reading and Writing: An Interdisciplinary Journal, 15, $109-126$

Breznitz, Z. (2001). The Determinants of Reading Fluency: A comparison of dyslexic and average readers. In M. Wolf (Ed.), Dyslexia, Fluency and the Brain (pp. 245-276). Cambridge, MA: York Press.

Brizzolara D, Chilosi A, Cipriani P, Di Filippo G, et al. (2006). Do phonologic and rapid automatized naming deficits differentially affect dyslexic children with and without a history of language delay? A study of Italian dyslexic children. Cognitive and Behavioral Neurology, 19 (3), 141-9.

Conrad, N. J., \& Levy, B. A. (2007). Letter processing and the formation of memory representations in children with naming speed deficits. Reading and Writing: An Interdisciplinary Journal, 20, 201223.

Carlisle, J. (1995). Morphological awareness and early reading achievement. In L. Feldman (Ed.) Morphological aspects of language processing (pp. 189-210). Hillsdale, N.J.: Lawrence Erlbaum Associates.

Carlisle J. (2000). Awareness of the structure and meaning of morphologically complex words: Impact on reading. Reading and Writing: An Interdisciplinary Journal, 12,169-190

Carlisle, J. F., \& Fleming, J. (2003). Lexical processing of morphologically complex words in the elementary years. Scientific Studies of Reading, 1, 239-253.

Carlisle, J., McBride-Chang, W., Nagy, W. E., \& Nunes, T. (2010). Effects of instruction morphological awareness on literacy achievement: An integrative review. Reading Research Quarterly, 45(4), 464-487.

Casalis, S., \& Louis-Alexandre, M.F. (2000). Morphological analysis, phonological analysis and learning to read French: A longitudinal study. Reading and Writing, 12,303-335.

Deacon, S. H. \& Kirby, J. R., (2004). Morphological awareness: Just "more phonological"? The role of morphological and phonological awareness in reading development. Applied Psycholinguistics, 25(2), 223-238.

Deacon, S. H., Wade-Woolley, L. \& Kirby, J. R. (2007). Cross-over: The role of morphological awareness in French immersion children's reading. Developmental Psychology, 43, 732-746.

De Jong, P., \& van der Leij, A. (2002). Effects of phonological abilities and linguistic comprehension on the development of reading. Scientific Studies of Reading, 6, 51-77.

Feldman, L. B., \& Bentin, S. (1994). Morphological analysis of disrupted morphemes: Evidence from Hebrew. Quarterly Journal of Experimental Psychology, 47, 407-435

Furnes, B., \& Samuelsson, S. (2010). Predicting reading and spelling difficulties in transparent and opaque orthographies: A comparison between Scandinavian and U.S./Australian children. Dyslexia,16, 119-142. 
Georgiou, G., Das, J. P., \& Hayward, D. (2008). Comparing the contribution of two tasks of working memory to reading in relation to phonological awareness and rapid naming speed. Journal of Research in Reading, 31, 302-318.

Georgiou, G.K., Parrila, R., \& Papadopoulos, T.C. (2008). Predictors of word decoding and reading fluency across languages varying in orthographic consistency. Journal of Educational Psychology, 100, 566-580.

Georgiou G. K., Parrila R., Cui Y., Papadopoulos T. C. (2013). Why is rapid automatized naming related to reading? J. Exp. Child Psychol. 115, 218-225 10.1016/j.jecp.2012.10.015

Gough, P.B. \& Tunmer, W.E. (1986). Decoding, reading, and reading disability. Remedial and Special Education, 7, 6-10.

Green, L. (2009). Morphology and literacy: Getting our heads in the game. Language, Speech, and Hearing Services in the schools, 40, 283-285.

Jiménez, J. E., \& Ramírez, G. (2002). Identifying subtypes of reading disability in the Spanish language. The Spanish Journal of Psychology, 5, 3-19.

Khomsi, A. (1999). LMC-R : Epreuve d'évaluation de la Compétence en Lecture. Lecture de mots et compréhension-révisée. L.M.C-R. Paris : Editions du Centre de Psychologie Appliquée.

Kieffer, M.J. \& Lesaux, N.K. (2008). The role of derivational morphological awareness in the reading comprehension of Spanish-speaking English language learners. Reading and Writing: An Interdisciplinary Journal, 21, 783-804.

Kirby, J.R., Deacon, S.H., Bowers, P.N., Izenberg, L., Wade-Woolley, L., \& Parilla, R. (2012). Children's morphological awareness and reading ability. Reading \& Writing: An Interdisciplinary Journal, 25(2), 389-410.

Kirby, J. R., Georgiou, G. K., Martinussen, R., \& Parrila, R. (2010). Naming speed and reading: From prediction to instruction. Reading Research Quarterly, 45, 341-362.

Kuo, L.-jen, \& Anderson, R. C. (2006). Morphological Awareness and Learning to Read: A Cross Language perspective. Educational Psychologist. 41, 161-180.

Landerl, K., \& Wimmer, H. (2008). Development of word reading fluency and spelling in a consistent orthography:An 8-year follow-up. Journal of Educational Psychology, 100, 150-161.

Landerl K, Ramus F, Moll K, Lyytinen H, Leppänen PH, Lohvansuu K, O'Donovan et al. (2012) Predictors of developmental dyslexia in European orthographies with varying complexity. Journal of Child Psychology and Psychiatry, 54(6),686-94.doi:10.1111/jcpp.12029

Layes S, Lalonde R, Rebaï M. (2015a) Reading speed and phonological awareness deficits among Arabic-speaking children with dyslexia. Dyslexia, 21(1):80-

95.doi:10.1002/dys.1491

\section{Layes S, Mecheri S, Lalonde R, Rebaï M (2015b) Phonological and cognitive reading related skills as predictors of word reading and reading comprehension among Arabic dyslexic children. Psychology, 6, 20-38. doi: 10.4236/psych.2015.61003.}

Leech, N. L., Barrett, K. C. \& Morgan, G. A. (2011). IBM SPSS for Intermediate Statistics: Use and Interpretation, $4^{\text {th }}$ ed.Routledge: New York. 
Lei, L., Pan,J., Liu,H., McBride-Chang,C., Li, H ., Zhang,Y., Chen,C...et al (2010). Developmental trajectories of reading development and impairment from ages 3 to 8 years in Chinese children. Journal of Child Psychology and Psychiatry, doi:10.1111/j.1469-7610.2010.02311.

McBride-Chang, C., Shu, H., Zhou, A., Wat, C.-P., \& Wagner, R. K. (2003).Morphological awareness uniquely predicts young children's Chinese character recognition. Journal of Educational Psychology, 95, 743-751.

Mahfoudhi, A., Elbeheri, G., Al-Rashidi, M. and Everatt, J. (2010) The Role of Morphological Awareness in Reading Comprehension Among Typical and Learning Disabled Native Arabic Speakers. Journal of Learning Disabilities 43(6),500-514.

Mahony, D., Singson, M. \& Mann, V. (2000). Reading ability and sensitivity to morphological relations. Reading and Writing: An Interdisciplinary Journal, 12,218 191 .

Mann, V. \& Wimmer, H. (2002). Phoneme awareness and pathways into literacy: A comparison of German and American children. Reading and Writing, 15, 653-682.

McBride-Chang, C., Liu, P. D., Wong, T., Wong, A. \& Maya, M., Katzir, T., Wolf, M., \& Poldrack, R. A. (2004).Neural systems for rapid automatized naming in skilled readers. Scientific Studies of Reading, 8, 241-256.

Nagy, W., Berninger, V. W., \& Abbott, R. D. (2006). Contribution of morphology beyond phonology to literacy outcomes of upper elementary and middle-school students. Journal of Educational Psychology, 98 (1), 134- 147

Nagy, W., Berninger, V., Abbott, R., Vaughan, K., \& Vermeulen, K. ( 2003).Relationship of morphology and other language skills to literacy skills in at-risk second-grade readers and at-risk fourth-grade writers. Journal of Educational Psychology, 95, 730-742.

Nation, K. (2005). Children's reading comprehension difficulties, in The Science of Reading: A Handbook, eds M. J. Snowing and C. Hulme, pp. 248-266, Blackwell, Oxford

Nunes, T., \& Bryant, P. (2006). Improving literacy by teaching morphemes. London: Routlege.

Parrila, R., Kirby, J. R., \& McQuarrie, L. (2004). Articulation rate, naming speed, verbal short-term memory, and phonological awareness: Longitudinal predictors of early reading development. Scientific Studies of Reading, 8, 3-26.

Powell, D., Stainthorp, R., Stuart, M., Garwood, H. \& Quinlan, P. (2007). An experimental comparison between rival theories of rapid automatized naming performance and its relationship to reading. Journal of Experimental Child Psychology, 98 (1), 46-68. doi: 10.1016/j.jecp.2007.04.003

Prunet, J.F., Beland, R., \& Idrissi, A.(2000) The mental representation of Semitic words. Linguistic Inquiry 31.4, 609-648.

Pugh, K. R., Landi, N., Preston, J.L., Mencl, E., Austin, A. C ., Sibley, D... et al. (2012). The relationship between phonological and auditory processing and brain organization in beginning readers. Brain \& Language, 125(2), 173-183.

Ramus, F., \& Ahissar, M. (2012). Developmental dyslexia: the difficulties of interpreting poor performance, and the importance of normal performance. Cognitive Neuropsychology, 29(1-2), 104-122

Roman, A. A., Kirby, J. R., Parrila, R., Wade-Woolley, L., \& Deacon, S. H. (2009). Toward a comprehensive view of the skills involved in word reading in Grades 4, 6, and 8. Journal of Experimental Child Psychology, 102, 96-113.

Saiegh-Haddad,E.(2005). Correlates of reading fluency in Arabic: Diglossic and orthographic factors. Reading and Writing, 18, 559-582

Saiegh-Haddad, E., \& Geva, E. (2008). Morphological awareness, phonological awareness, and reading in English-Arabic bilingual children. Reading and Writing: An Interdisciplinary Journal, 21, 481-504.

Shimron, J.(2003). Language Processing and Acquisition in Languages of Semitic, Root-based, 


\section{Morphology, John Benjamins Publishing}

Shu, H., McBride-Chang, C., Wu, S., \& Liu, H. (2006). Understanding Chinese developmental dyslexia: morphological awareness as a core cognitive construct. J. Educ. Psychol. 98, 122-133

Siegel, L.S. (2008) Morphological awareness skills of English language learners and children with dyslexia. Topics in Language Disorders, 28 (1), 15-27.

Singson, M., Mahony, D. \& Mann, V. (2000). The relation between reading ability and morphological skills: Evidence from derivational suffixes. Reading and Writing: An Interdisciplinary Journal, 12, 219-252.

Snowling, M. J., \& Hulme, C. (2012). Children's reading impairments: From theory to practice. Japanese Psychological Research, 55 (2), 186-202

Taha H. Y. (2013) Investigating Cognitive Processes Underlying Reading in Arabic: Evidence from Typical and Poor Reading Performance. Psychology, 04 (12), 1018 1026. doi:10.4236/psych.2013.412148.

Taha, H. Y., \& Saiegh-Haddad, E. (Submitted). Morphology and spelling in Arabic: Development and interface.

Tong, X., Deacon, S. H., Kirby, J.R., Cain, K.,Parrila, R (2011). Morphological awareness: A key to understanding poor reading comprehension in English. Journal of Educational Psychology, 103(3) . doi: $10.1037 / \mathrm{a} 0023495$

Torgesen, J. K., Wagner, R. K., \& Rashotte, C. A. (1994). Longitudinal studies of phonological processing and reading. Journal of Learning Disabilities, 27, 276-286

Vaessen, A. A., \& Blomert, L. (2010). Long-term cognitive dynamics of fluent reading development. Journal of Experimental Child Psychology, 105, 213-231.

Vaessen, A., Bertrand, D., Tóth, D., Csépe, V., Faísca, L., Reis, A., et al. (2010). Cognitive development of fluent word reading does not qualitatively differ between transparent and opaque orthographies. Journal of Educational Psychology, 102,827-842

Verhoeven, L., \& Perfetti, C. A. (2008). Introduction. Advances in text comprehension: Model, process and development. Applied Cognitive Psychology, 22(3), 293-301.

Wagner, R. K., Torgesen, J. K., Rashotte, C. A., Hecht, S. A., Barker, T. A., Burgess, S. R., et al. (1997). Changing relations between phonological processing abilities and word-level reading as children develop from Beginning to Skilled Readers: A 5-Year Longitudinal Study. Developmental Psychology, 33 (3) 468-479

Wolf, M., Bowers, P. \& Biddle, K. (2000). Naming-speed processes, timing, and reading: A conceptual review, Journal of Learning Disabilities.33, 387-407.

Wolff,U. (2014). RAN as a predictor of reading skills, and vice versa: results from a randomized reading intervention. Annals of Dyslexia.

Wolter, J.A., Wood, A., \& D'zatko, K. (2009). The influence of morphological awareness on first-grade children's literacy development. Language, Speech, Hearing Services in the Schools, 40(3),1-13.

Zar, J.H. (1996). Biostatistical analysis. 3rd ed. London: Prentice Hall International.

Ziegler, J.C., Pech-Georgel, C., Dufau, S., \& Grainger, J. (2010). Rapid processing of letters, digits and symbols: what purely visual-attentional deficit in developmental dyslexia? Developmental Science, 13, 8-14. 
Table 1. Participant's characteristics and mean performance in all measures by group: Dyslexics, Age- matched Controls (A.C) and Younger Controls (Y.C). (Standard deviations in parentheses).

\begin{tabular}{|c|c|c|c|c|c|}
\hline \multirow[b]{2}{*}{ Variables } & Dyslexics & Age Matched & $\begin{array}{l}\text { Younger } \\
\text { Controls }\end{array}$ & \multirow[b]{2}{*}{$\mathrm{F}(2.55)$} & \multirow[b]{2}{*}{ Group comparisons } \\
\hline & $\frac{(\mathrm{N}=20)}{\mathrm{M}(\mathrm{SD})}$ & $\frac{(\mathrm{N}=20)}{\mathrm{M}(\mathrm{SD})}$ & $\mathrm{M} \quad(\mathrm{SD})$ & & \\
\hline Age & $133.60(8.37)$ & $130.30(4.76)$ & $116.83(5.12)$ & $36.62 * * *$ & A.C $=$ DYS > Y.C \\
\hline Raven (Raw scores) & $25.90(3.00)$ & $29.35(4.72)$ & $22.78(5.24)$ & $10.62 * * *$ & A.C $>$ DYS $=$ Y.C \\
\hline
\end{tabular}




\begin{tabular}{llllll} 
Total reading words & $29.40(13.90)$ & $60.45(7.12)$ & $60.56(19.9)$ & $57.28^{* * *}$ & A.C $=$ Y.C $>$ DYS \\
Frequent words & $18.05(8.40)$ & $33.40(3.74)$ & $31.44(5.45)$ & $35.93^{* * *}$ & A.C $=$ Y.C $>$ DYS \\
Infrequent words & $11.35(7.06)$ & $27.05(4.93)$ & $29.11(4.72)$ & $56.56^{* * *}$ & A.C $=$ Y.C $>$ DYS \\
Pseudo Words & $5.85(4.64)$ & $14.05(3.05)$ & $14.33(4.15)$ & $28.41^{* * *}$ & A.C $=$ Y.C $>$ DYS \\
Reading Comprehension & $9.85(3.60)$ & $13.64(1.24)$ & $14.16(1.32)$ & $20.42^{* * *}$ & A.C $=$ Y.C $>$ DYS \\
Morpho. Awareness & & & & \\
Morphology Dismantling & $6.45(4.52)$ & $9.75(5.05)$ & $5.17(4.87)$ & $4.63^{* *}$ & A.C $>$ DYS $=$ Y.C \\
Morphology Production & $11.75(7.92)$ & $23.80(9.50)$ & $11.17(5.35)$ & $16.15^{* * *}$ & A.C $>$ Y.C $=$ DYS \\
Pattern Recognition & $12.85(3.85)$ & $17.10(1.91)$ & $14.06(3.45)$ & $9.46^{* * *}$ & A.C $>$ DYS $=$ Y.C \\
Ortho-Morphology Form & $5.75(2.65)$ & $7.80(2.56)$ & $7.28(2.78)$ & $3.18^{*}$ & A.C $>$ DYS $=$ Y.C \\
Relation Judgment & $15.15(3.10)$ & $16.70(3.49)$ & $17.22(3.60)$ & 1.94 n.s & \\
Total Morphology & $51.95(14.56)$ & $75.15(15.38)$ & $54.89(12.87)$ & $15.30^{* * *}$ & A.C $>$ DYS $=$ Y.C \\
RAN & & & & \\
RAN Objects & $43.60(17.05)$ & $27.05(5.97)$ & $35.33(17.95)$ & $6.44^{* * *}$ & A.C $>$ DYS $=$ Y.C \\
RAN Shapes & $38.95(25.00)$ & $29.35(7.46)$ & $30.50(9.21)$ & $2.02 \mathrm{n} . \mathrm{s}$ & \\
RAN Digit & $62.35(25.44)$ & $45.65(18.68)$ & $57.39(19.42)$ & $3.18^{*}$ & A.C $>$ DYS $=$ Y.C \\
Total RAN & $144.90(53.16)$ & $102.05(23.59)$ & $123.22(29.91)$ & $6.66^{* * *}$ & A.C $>$ DYS $=$ Y.C \\
\hline
\end{tabular}

$* \mathrm{P}<0.05 ; * * \mathrm{P}<0.01 ; * * * \mathrm{P}<0.001 ;$ n.s. $=$ not significant.

Table.2 Partial correlations controlling for Age and IQ for normal readers $(n=38)$ above the diagonal, and for dyslexics $(n=20)$ below the diagonal

\begin{tabular}{llllllll}
\hline Variables & F.W & I.W & T.W.R & P.W & R.C & M.A & RAN \\
\hline Frequent Words (F.W) & & $.46^{* * *}$ & $.85^{* * *}$ & $.43^{* * *}$ & .29 & .26 & - \\
Infrequent Words (I.W) & $.65^{* * *}$ & & $.86^{* * *}$ & $.36^{*}$ & $.37^{* *}$ & .23 & $-.47^{* * *}$
\end{tabular}




\begin{tabular}{|c|c|c|c|c|c|c|c|}
\hline Total Words Reading (T.W.R) & $.92 * * *$ & $.89 * * *$ & & $.46 * * *$ & $.39 *$ & .29 & $-.55 * * *$ \\
\hline Pseudo Words (P.W) & -.23 & .06 & -.10 & & $.32 *$ & $.44 * * *$ & $-.32 *$ \\
\hline Reading Comprehension (R.C) & .10 & .30 & .21 & .41 & & $.40 * *$ & -.30 \\
\hline Morphological Awareness (M.A) & -.16 & .07 & -.06 & .29 & $.68 * * *$ & & -.30 \\
\hline Total RAN (RAN) & -.02 & .20 & .09 & -.24 & -.23 & $-.51 *$ & \\
\hline
\end{tabular}

$* \mathrm{P}<0.05 ; * * \mathrm{P}<0.01 ; * * * \mathrm{P}<0.001$

Table.3 Summary of Hierarchical Regression predicting word recognition and reading comprehension for the entire sample $(\mathrm{N}=58)$

\begin{tabular}{|c|c|c|c|c|c|c|c|c|}
\hline \multirow[b]{2}{*}{ Variables } & \multicolumn{4}{|c|}{ Word Reading } & \multicolumn{4}{|c|}{ Reading Comprehension } \\
\hline & $\beta$ & $t$ & F change & Total $R^{2}$ & $\beta$ & $t$ & $F$ change & Total $R^{2}$ \\
\hline Age & -.46 & $-3.60 * * *$ & $6.90 * * *$ & .20 & -.70 & $-6.55 * * *$ & $22.15^{* * *}$ & .44 \\
\hline Raven & .26 & $2.08 *$ & & & .35 & $3.32 * * *$ & & \\
\hline
\end{tabular}




\begin{tabular}{|c|c|c|c|c|c|c|c|c|}
\hline RAN Objects & -.30 & $-2.32 *$ & $3.09 *$ & .12 & -.31 & $-3.11 * * *$ & $6.45 * * *$ & .15 \\
\hline RAN Shapes & .008 & .06 & & & -.14 & -1.41 & & \\
\hline RAN Digits & -.11 & -.90 & & & .008 & -.08 & & \\
\hline Pseudo words & .60 & $4.55 * * *$ & $20.75^{* * *}$ & .19 & .43 & $4.17 * * *$ & $17.45 * * *$ & .10 \\
\hline \multicolumn{9}{|l|}{ Morphological Awareness } \\
\hline Morphology Dismantling & -.19 & -1.47 & .74 & .03 & -.008 & .08 & $2.65^{*}$ & .06 \\
\hline Morphology Production & .004 & .02 & & & .14 & 1.41 & & \\
\hline Pattern Recognition & .10 & .78 & & & .06 & .71 & & \\
\hline Ortho-Morphology Form & -.09 & -.73 & & & .13 & 1.45 & & \\
\hline Relation Judgment & .11 & 1.01 & & & .16 & $1.96^{*}$ & & \\
\hline
\end{tabular}

$* \mathrm{P}<0.05 ; * * \mathrm{P}<0.01 ; * * * \mathrm{P}<0.001$

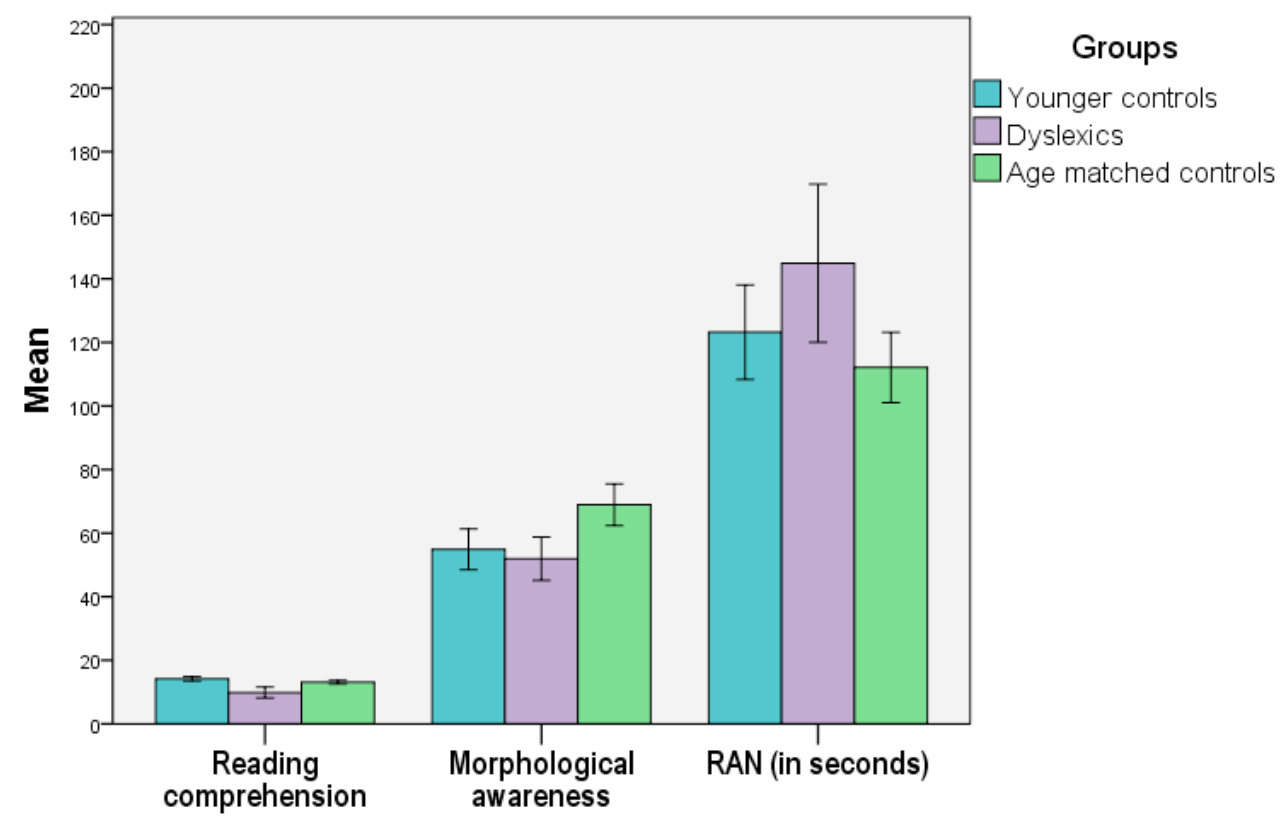

Figure 1. Participant's performances in RC, MA and RAN measures 
